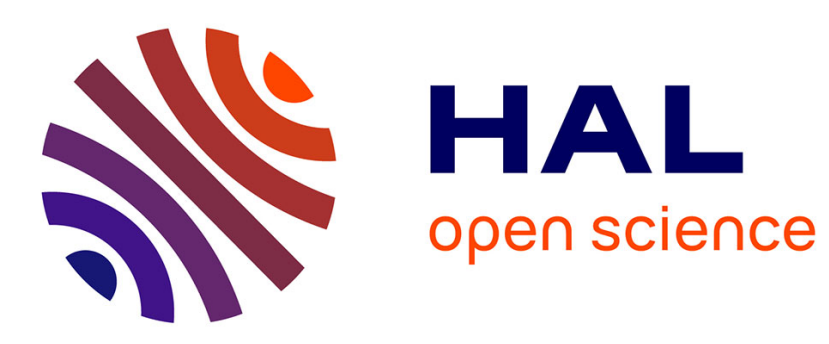

\title{
Intumescent polypropylene in extreme fire conditions
}

Serge Bourbigot, Johan Sarazin, Tsilla Perez

\section{To cite this version:}

Serge Bourbigot, Johan Sarazin, Tsilla Perez. Intumescent polypropylene in extreme fire conditions. Fire Safety Journal, 2020, 120, pp.103082. 10.1016/j.firesaf.2020.103082 hal-02926318v2

\section{HAL Id: hal-02926318 \\ https://hal.univ-lille.fr/hal-02926318v2}

Submitted on 28 May 2021

HAL is a multi-disciplinary open access archive for the deposit and dissemination of scientific research documents, whether they are published or not. The documents may come from teaching and research institutions in France or abroad, or from public or private research centers.
L'archive ouverte pluridisciplinaire HAL, est destinée au dépôt et à la diffusion de documents scientifiques de niveau recherche, publiés ou non, émanant des établissements d'enseignement et de recherche français ou étrangers, des laboratoires publics ou privés. 
1 Intumescent polypropylene in extreme fire conditions

2 Serge Bourbigot ${ }^{\mathrm{a}^{*}}$, Johan Sarazin ${ }^{\mathrm{a}}$, Tsilla Bensabath ${ }^{\mathrm{a}}$

3 aUniv. Lille, ENSCL, UMR 8207 - UMET - Unité Matériaux et

4 Transformations, France, serge.bourbigot@ensc-lille.fr

$5 \quad *$ Corresponding author

6

\title{
Highlights:
}

- Intumescent polypropylene (PP) can resist to burnthrough test

- Long time of piercing using zinc borate as synergist

- Borophosphates forming a glass reinforcing the intumescent char

\begin{abstract}
:
The paper deals with intumescent polypropylene (PP) undergoing extreme fire (burn-through test with heat flux higher than $100 \mathrm{~kW} / \mathrm{m}^{2}$ ). The purpose of this unusual approach is to explore the possibility to design intumescent plastic (here PP) resisting to burn-through test. A combination of commercial intumescent flame retardants (ammonium polyphosphate-based compounds containing a char former; AP766 (AP) and FlameOff (FO) of the companies Clariant and FlameOff Inc) with zinc borate (supplied by US Borax, ZB) or Kemgard (combination of ZB and molybdate supplied by Huber, KZ) was incorporated in PP. Use of ZB and $\mathrm{KZ}$ as synergists in FO formulations increases dramatically the time of piercing (formation of hole through the plaque of polymer at $80 \mathrm{~s}$ without $\mathrm{ZB}$ or $\mathrm{KZ}$ vs. $280 \mathrm{~s}$ with $\mathrm{KZ}$ ) at the burn-through test (heat flux $=116 \mathrm{~kW} / \mathrm{m}^{2}$, propane burner) while the combination with AP does not show any benefit. Analyses of the residues obtained at different times of combustion by solid state nuclear magnetic resonance (NMR) of ${ }^{31} \mathrm{P},{ }^{11} \mathrm{~B}$ and ${ }^{13} \mathrm{C}$ shows the formation of borophosphates creating a glass reinforcing the intumescent char: it acts as a 'glue' providing flexibility and cohesion to the char.
\end{abstract}

Keywords: intumescence, fire chemistry, burn-through, polypropylene

\section{Introduction}

There is not a commonly accepted definition of the concept of 'extreme fire'. According to its common use the expression 'extreme fire' is a complex 
entity as it involves different realities and ways of looking. It contains at least three concepts [1]: (i) an idea of extension in the sense that 'extreme fire behavior' is very commonly associated to very large fires or fires that extend in large areas during extended periods of time; (ii) an idea of intensity in the sense that some properties of fire spread, namely its rate of spread or its rate of energy release acquire very large values; (iii) a third idea that is associated to 'extreme fire behavior' is related to rapid change in fire behavior conditions that is also linked to some degree of uncertainty in its prediction and danger. In this paper, we only kept the idea of high rate of energy.

It is common practice by fire scientists to quantify the intensity of a fire by the radiant heat flux rather than flame temperature [2]. There is an approximate relationship between fire type and heat flux but we should recognize it is a crude assumption because the incident heat fluxes depend on the spatial arrangement between the flame and the receiving target. The examples give a direct measurement of the heat flux from the source and they are: (i) small smoldering fire: $2-10 \mathrm{~kW} / \mathrm{m}^{2}$; (ii) trash can fire: $10-50$ $\mathrm{kW} / \mathrm{m}^{2}$; (iii) room fire, open pool fire: $50-100 \mathrm{~kW} / \mathrm{m}^{2}$; (iv) post-flashover room fire, confined pool fire: $>100 \mathrm{~kW} / \mathrm{m}^{2}$, (v) jet fuel fire, open jetfire: 100 $200 \mathrm{~kW} / \mathrm{m}^{2}$ and (vi) confined jetfire, BLEVE: $>200 \mathrm{~kW} / \mathrm{m}^{2}$. In this research, heat flux corresponding to open jetfire or jet fuel fire was considered (it is high energy and hence it can be considered as extreme fire). Higher heat fluxes were not selected because the purpose was to investigate the response of an intumescent polypropylene (PP) in unconventional conditions for fire testing.

The intumescence process results from a combination of charring and foaming at the surface of the substrate [3]. The result of this process is the formation of a multicellular (alveolar) barrier, thick and non-flammable, which protects the substrate or residual material from heat or flame action. The charred layer acts as a physical barrier which slows down heat and mass transfer between gas and condensed phase. The formation of an intumescent char is a complicated process involving several critical aspects: rheology (expansion phase, viscoelasticity of char), chemistry (charring) and thermophysics (limitation of heat and mass transfer) [4]. This concept of intumescence enables to make flame retarded (FR) polymeric materials (including PP-based materials) exhibiting high performance in the case of reaction to fire (contribution of the material to fire growth) [5]. FR PPs are not used in the case of resistance of fire (ability of materials to resist the passage of fire and/or gaseous products of combustion), i.e. fire scenarios corresponding to burn-through, jetfire or structural response to fire, because they are not designed for this: they soften upon heating and fire can spread 
out. Nevertheless, intumescent coatings applied on steel or composite act as efficient fire barrier and we believe we should reach acceptable performance using intumescent thermoplastics in the case of resistance of fire. It is an unconventional testing for thermoplastics and no paper reports this type of approach. At this time, there is no specific application for this type of materials and the motivation of this paper is to explore the possibility to design intumescent plastic (here PP) resisting to burn-through test.

The paper is organized in three parts. The first part is devoted to the design of the intumescent formulation in PP considering potential synergists. Based on the results of the first part, the second part deals with the determination of mechanism of action using specific analyses by solid state nuclear magnetic resonance (NMR). Finally, the effect of the fillers content (loading) determined in the first part and incorporated in PP is examined in the third part.

\section{Experimental}

\subsection{Materials}

Commercial grade of PP was used in this work: PP (ISPLEN PP 089 Y1E) was supplied by Repsol (Madrid, Spain). PP 089 Y1E has a melt flow rate (MFR) for a load of $2.16 \mathrm{~g}$ at $230^{\circ} \mathrm{C}$ of $31 \mathrm{~g} / 10 \mathrm{~min}$. Modified ammonium polyphosphate (AP) is the commercial grade of Clariant (Knapsak, Germany) with the brand name Exolit AP766. It is an intrinsic intumescent system containing $24 \mathrm{wt} \%$ phosphorus and $15 \mathrm{wt} \%$ nitrogen acting in synergy. Another modified ammonium polyphosphate as a powder was used from the company FlameOff (Raleigh, NC - USA) and hereafter called FO (the composition is proprietary). Zinc borate (ZB) was added in combination with the intumescent additives as potential synergist. Its composition is $2 \mathrm{ZnO} \cdot 3 \mathrm{~B}_{2} \mathrm{O}_{3}$ and it was supplied by the company US Borax (Boron, CA USA) under the brand name Firebrake. Kemgard $700 \mathrm{Z}$ is a complex mixture of zinc molybdate/zinc borate (the composition is proprietary) from the company Huber Engineered Materials (Atlanta, GA - USA): it was also used in combination with the intumescent additives as potential synergist and it is hereafter called $\mathrm{KZ}$.

\subsection{Processing and formulations}

The strategy was to blend PP with FRs in a twin-screw extruder. The total loading of FRs in PP was between 30 and $50 \mathrm{wt} \%$ varying the ratio between the intumescent additives (AP or FO) and the synergists ( $\mathrm{ZB}$ or KZ). The 
115 formulations prepared in this work are gathered in Table 1. Note the loading 116 of $\mathrm{ZB}$ and $\mathrm{KZ}$ is low compared to AP and FO to get the highest 117 reinforcement of the intumescent char $[6,7]$.

118

119

120

Table 1. Formulations of the intumescent PPs

\begin{tabular}{|c|c|c|c|c|c|}
\hline Formulation & PP (wt\%) & $\begin{array}{c}\text { AP } \\
(w t \%)\end{array}$ & $\begin{array}{c}\text { FO } \\
(\mathrm{wt} \%)\end{array}$ & $\begin{array}{c}\text { ZB } \\
(w t \%)\end{array}$ & $\begin{array}{c}\mathrm{KZ} \\
(\mathrm{wt} \%)\end{array}$ \\
\hline PP & 100 & 0 & 0 & 0 & 0 \\
\hline $\mathrm{PP}(70)-\mathrm{AP}$ & 70 & 30 & 0 & 0 & 0 \\
\hline $\begin{array}{l}\mathrm{PP}(70)- \\
\mathrm{AP} / \mathrm{ZB}(28: 2)\end{array}$ & 70 & 28 & 0 & 2 & 0 \\
\hline $\mathrm{PP}(70)-\mathrm{FO}$ & 70 & 0 & 30 & 0 & 0 \\
\hline $\begin{array}{l}\mathrm{PP}(70)- \\
\mathrm{FO} / \mathrm{ZB}(29: 1)\end{array}$ & 70 & 0 & 29 & 1 & 0 \\
\hline $\begin{array}{l}\mathrm{PP}(70)- \\
\mathrm{FO} / \mathrm{ZB}(28: 2)\end{array}$ & 70 & 0 & 28 & 2 & 0 \\
\hline $\begin{array}{l}\mathrm{PP}(70)- \\
\mathrm{FO} / \mathrm{ZB}(27: 3)\end{array}$ & 70 & 0 & 27 & 3 & 0 \\
\hline $\begin{array}{l}\mathrm{PP}(70)- \\
\mathrm{FO} / \mathrm{ZB}(25: 5)\end{array}$ & 70 & 0 & 25 & 5 & 0 \\
\hline $\begin{array}{l}\mathrm{PP}(70)- \\
\mathrm{FO} / \mathrm{KZ}(29: 1)\end{array}$ & 70 & 0 & 29 & 0 & 1 \\
\hline $\begin{array}{l}\mathrm{PP}(70)-\mathrm{FO} / \mathrm{KZ} \\
(28: 2)\end{array}$ & 70 & 0 & 28 & 0 & 2 \\
\hline $\begin{array}{l}\mathrm{PP}(70)-\mathrm{FO} / \mathrm{KZ} \\
(27: 3)\end{array}$ & 70 & 0 & 27 & 0 & 3 \\
\hline $\begin{array}{l}\mathrm{PP}(70)-\mathrm{FO} / \mathrm{KZ} \\
(25: 5)\end{array}$ & 70 & 0 & 25 & 0 & 5 \\
\hline $\begin{array}{l}\mathrm{PP}(50)- \\
\mathrm{FO} / \mathrm{ZB}(29: 1)\end{array}$ & 50 & 0 & 48.3 & 1.7 & 0 \\
\hline $\begin{array}{l}\mathrm{PP}(50)- \\
\mathrm{FO} / \mathrm{ZB}(28: 2)\end{array}$ & 50 & 0 & 46.7 & 3.3 & 0 \\
\hline $\begin{array}{l}\mathrm{PP}(50)- \\
\mathrm{FO} / \mathrm{ZB}(27: 3)\end{array}$ & 50 & 0 & 45 & 5 & 0 \\
\hline $\begin{array}{l}\mathrm{PP}(50)- \\
\mathrm{FO} / \mathrm{ZB}(25: 5)\end{array}$ & 50 & 0 & 41.7 & 8.3 & 0 \\
\hline $\begin{array}{l}\mathrm{PP}(50)- \\
\mathrm{FO} / \mathrm{KZ}(29: 1)\end{array}$ & 50 & 0 & 48.3 & 0 & 1.7 \\
\hline $\begin{array}{l}\mathrm{PP}(50)-\mathrm{FO} / \mathrm{KZ} \\
(28: 2)\end{array}$ & 50 & 0 & 46.7 & 0 & 3.3 \\
\hline $\begin{array}{l}\mathrm{PP}(50)-\mathrm{FO} / \mathrm{KZ} \\
(27: 3)\end{array}$ & 50 & 0 & 45 & 0 & 5 \\
\hline $\begin{array}{l}\mathrm{PP}(50)-\mathrm{FO} / \mathrm{KZ} \\
(25: 5)\end{array}$ & 50 & 0 & 41.7 & 0 & 8.3 \\
\hline
\end{tabular}



screw extruder. The extruder is a co-rotating intermeshing twin screw with a barrel length of $400 \mathrm{~mm}$ and screw diameter of $16 \mathrm{~mm}(\mathrm{~L} / \mathrm{D}=25)$ with 10 zones. PP and FRs were incorporated using two gravimetric side feeders into the extruder. Polymer flow rate is fixed to extrude about $500 \mathrm{~g} / \mathrm{h}$ with a screw speed of $300 \mathrm{rpm}$. The temperature profile of the extruder from feeder to die was set at $200 / 200 / 200 / 200 / 200 / 170 / 185 / 180 / 200 / 200^{\circ} \mathrm{C}$.

\subsection{Burn-through test}

In a previous work, a versatile fire test was developed with a complete set of instrumentation to investigate the fire behavior of materials. The description of this test is fully described in [8] and the reader could find all information about the setup and the measurement. In this paper, only required information to describe the operation of the test is given. This test is a burn-through test which was designed to mimic the aeronautical fire test defined in the standard ISO2685:1998. In this work, it was used as burnthrough test and to create an extreme fire for fire-retarded thermoplastics. The equipment is described as follows and is shown in Fig. 1: (i) Propane burner from Bullfinch, (ii) High purity propane supplied by Air Liquide (N35, purity 99.95\%), (iii) Propane flowmeter from Bronkhorst High-tech, (iv) Water-cooled heat flux gauge from Sequoia, (v) Cooling thermostat from Lauda Brinkmann (Lauda Proline RP845), (vi) Infrared (IR) camera from FLIR SystemsTM (ThermovisionTM A40M Researcher) calibrated from $0^{\circ} \mathrm{C}$ to $1000^{\circ} \mathrm{C}$ and (vii) Fireproof panels composed of silicate of calcium from Final Advanced Materials (Calsil) of $10 \mathrm{~mm}$ thick.

The burner can deliver a propane-air flame characterized by a heat flux up to $200 \mathrm{~kW} / \mathrm{m}^{2}$. The burner was placed at $75 \mathrm{~mm}$ from the material and the heat flux was calibrated at $116 \mathrm{~kW} / \mathrm{m}^{2}$ using a heat flux gauge in the same conditions as the tested sample in a separate box (error less than 5\%). The temperature of the flame was measured with 5 aligned thermocouples (along the flame) at $1100^{\circ} \mathrm{C}$. The sample size was $10 \times 10 \mathrm{~cm}^{2}$ and was put between the two panels in Calsil (see above). Temperature was measured in the center of the sample using a thermocouple embedded in the polymer at the surface of its backside. Infrared camera was also used to estimate the surface temperature assuming the emissivity of the surface constant equaling 0.92 (black paint of known emissivity on the backside of the polymer plaque). Reasonable agreement was observed between the two measurements and only temperature measured by the thermocouple was shown in the following. All experiments were repeated at least twice and all 
measurements were within $10 \%$ error (in [8], we showed the error on temperature measurement was less than $10 \%$ ).

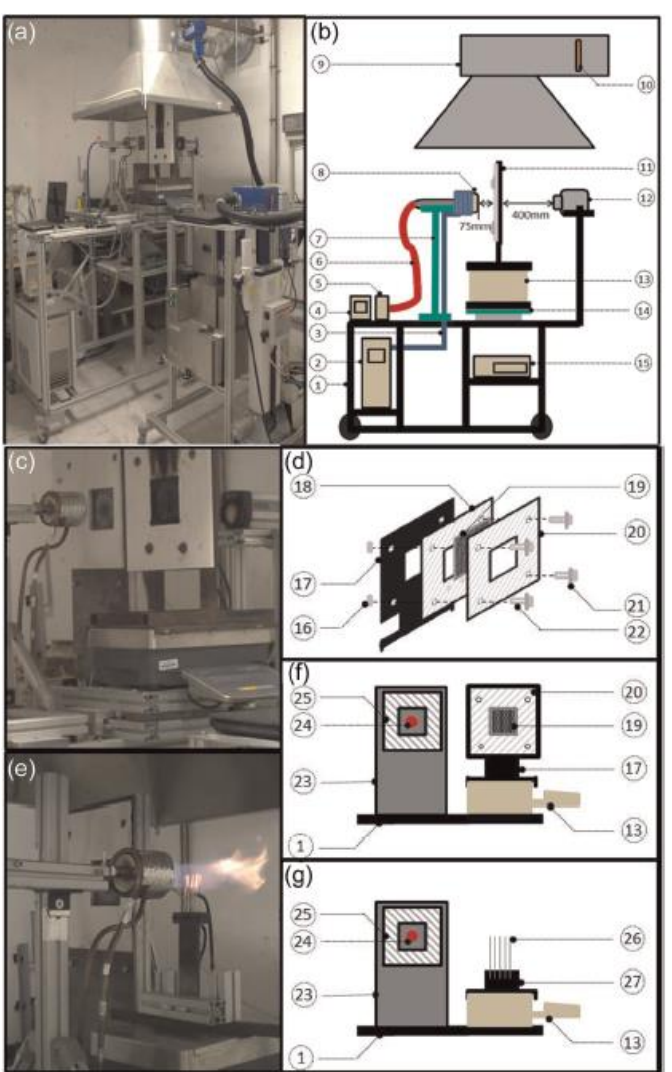

Fig. 1. Picture (a, c, e) and scheme (b, d, f, g) of the experimental apparatus - (1) Test bench frame, (2) Cooling system, (3) Copper coil cooler, (4) Propane thermocontroller, (5) Propane flowmeter, (6) Propane gas line, (7) Burner support, (8) Propane flame burner, (9) Hood, (10) Ring sampler, (11) Sample holder, (12) Infrared (IR) camera, (13) Precision scale, (14) Scale holder, (15) Data acquisition device, (16) Bolt, (17) Steel support, (18) Fireproof boards, (19) Sample, (20) Fireproof boards, (21) Washer, (22) Screw, (23) Water-cooled calorimeter holder, (24) Water-cooled calorimeter, (25) Fireproof panel, (26) Aligned thermocouples, (27) Thermocouple holder (adapted from [8])

\subsection{NMR analyses}

${ }^{11} \mathrm{~B}$ magic angle spinning - nuclear magnetic resonance (MAS-NMR) was performed at $256.6 \mathrm{MHz}$ on a $18.8 \mathrm{~T}$ Bruker Avance III spectrometer with a $3.2 \mathrm{~mm}$ probehead operating at a spinning frequency $\left(v_{\text {rot }}\right)$ of $20 \mathrm{kHz}$. The spectra were recorded with a $1 \mathrm{~ms}$ pulse length (corresponding to a $\pi / 12 \mathrm{flip}$ angle determined on a liquid), a recycle delay (rd) of $10 \mathrm{~s}$ and 128 transients. ${ }^{13} \mathrm{C}$ and ${ }^{31} \mathrm{P}$ MAS-NMR experiments were performed on a $9.4 \mathrm{~T}$ Bruker 
Avance spectrometer at 100.6 and $162 \mathrm{MHz}$, respectively. The ${ }^{13} \mathrm{C}\left({ }^{1} \mathrm{H}\right)$ cross-polarization (CP) NMR experiment was conducted with a $4 \mathrm{~mm}$ probehead at $v_{\text {rot }}$ of $10 \mathrm{kHz}$ with a $4 \mathrm{~ms}$ pulse length (corresponding to a $\pi / 2$ flip angle), a rd of $10 \mathrm{~s}$, a contact time of $1 \mathrm{~ms}$ and 1024 transients. The ${ }^{31} \mathrm{P}$ NMR analysis was carried out with a $4 \mathrm{~mm}$ probehead under $1 \mathrm{H}$ decoupling conditions. The spectrum was recorded with a $\nu_{\text {rot }}$ of $12.5 \mathrm{kHz}$, a $2 \mu$ s pulse length (corresponding to a $\pi / 4$ flip angle) a rd of $120 \mathrm{~s}$ and 16 transients. ${ }^{11} \mathrm{~B}$ and ${ }^{31} \mathrm{P}$ chemical shifts were referred to $\mathrm{NaBH}_{4}$ and $\mathrm{H}_{3} \mathrm{PO}_{4}$ at $-42.06 \mathrm{ppm}$ and $0 \mathrm{ppm}$, respectively.

\section{Results and discussion}

\subsection{Design of the intumescent formulation}

Intumescent PPs are generally designed to exhibit high performance in terms our goal to examine the ability of intumescent PPs to resist to burn-through test. This condition is unusual for commodity polymer such as PP but intumescence is also used as protective coating for diverse substrates (e.g. steel, wood or composites) to pass the burn-through test. Two types of additives were incorporated in PP: (i) AP is a conventional intumescent additive providing low flammability to $\mathrm{PP}$ for various fire scenarios such as UL-94, glow wire or cone calorimeter and (ii) FO is a new intumescent additive on the market and was made from intumescent ingredients of intumescent paint. Based on previous works of this lab, zinc borate was selected as potential synergist because it is known to reinforce intumescent char [6]. ZB is a pure zinc borate and was already used in previous formulations [7] but $\mathrm{KZ}$ has never been evaluated in combination with intumescent ingredients. This last product was selected because its main composition is zinc borate and to take advantage of the presence of molybdate (known as synergist with metal hydroxides).

Intumescent PPs filled at $30 \mathrm{wt} \%$ loading were first evaluated (Fig. 2). The temperature rise in all materials is similar up to $40 \mathrm{~s}$. Virgin PP softens when it reaches $140^{\circ} \mathrm{C}$ on its backside (melting temperature of $\mathrm{PP}$ is in the range $150-170^{\circ} \mathrm{C}$ ) and it pierces just after (sharp increase of temperature at $150^{\circ} \mathrm{C}$ ). When AP and AP/ZB (ratio 28 to 2) are incorporated in PP, char formation at the surface of the material can be observed but it cannot extend the time to piercing. Visual observation suggests the expansion of the char is not fast enough to provide a protection and it remains too soft to resist to the impingement of the flame. In this case, there is no benefit to combine ZB with the intumescent additive. On the contrary, the incorporation of FO slows the temperature rise after $40 \mathrm{~s}$ thanks to the formation of an 
intumescent char. The char resists to the impingement of the flame up to 90 $\mathrm{s}$ and it pierces after because of the too high softening of the material. The addition of $\mathrm{ZB}$ in the formulation dramatically improves the resistance to piercing of the system. The time to piercing is reached at $225 \mathrm{~s}$ thanks to the fast formation of an intumescent char which remains rigid (low softening) for longer times.

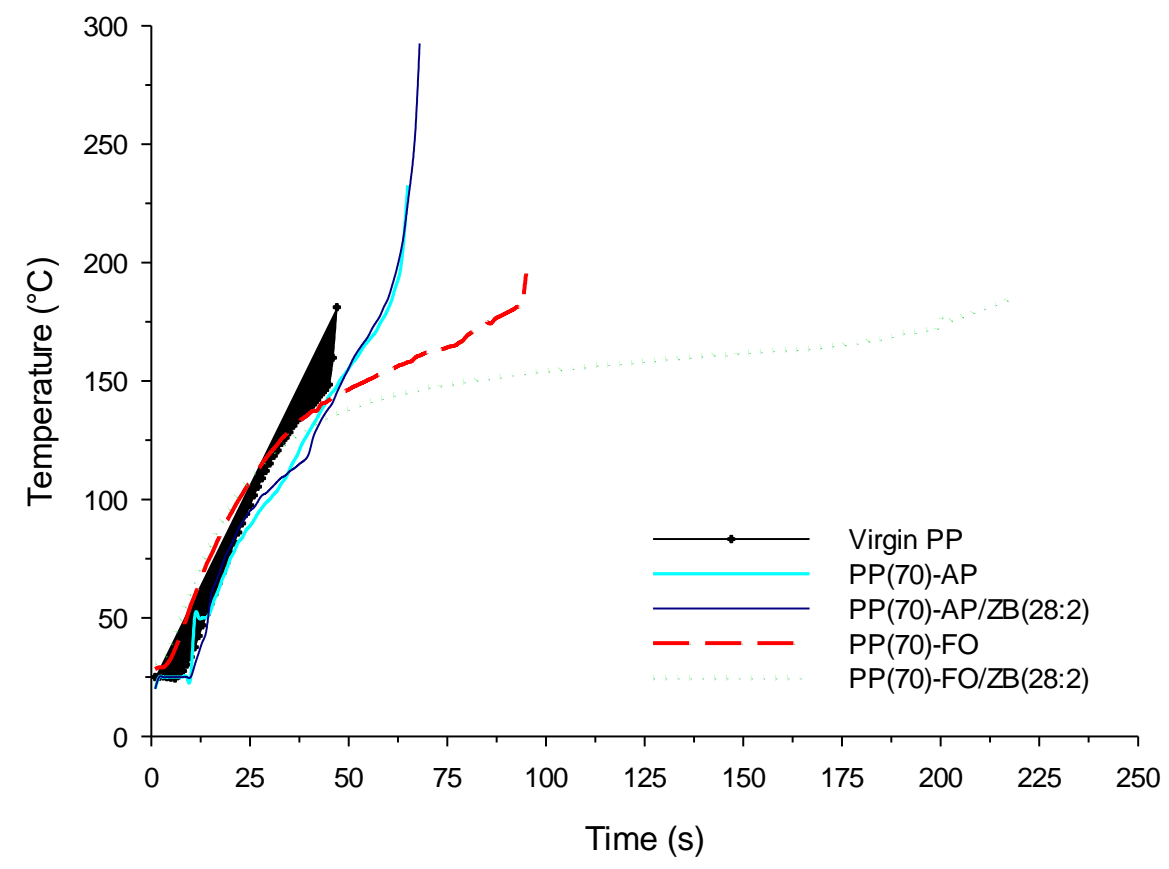

Fig. 2. Temperature as a function of time on the backside of intumescent PPs containing $\mathrm{AP}$ and $\mathrm{FO}$ as main ingredient during a burn-through test at $116 \mathrm{~kW} / \mathrm{m}^{2}$.

From the results above, it is shown AP is not the right additive for PP to perform the burn-through test. In the following, we only focus our work on $\mathrm{FO}$ in combination with $\mathrm{ZB}$ and on determining the best ratio FO/ZB. We kept the loading of $\mathrm{ZB}$ low compared to FO (Table 1) because our previous work showed the ratio intumescent formulation over $\mathrm{ZB}$ should be high enough (typically 28:2) to get the highest efficiency of ZB [7]. Fig. 3 -(a) shows the temperature/time curves of the formulations varying the ratio FO/ZB compared to virgin PP and PP(70)-FO. The formulation having the ratio 29:1 pierces at $125 \mathrm{~s}$ and so, it does not show any enhancement compared to the ratio $28: 2$. Note the performance is highly sensitive to the content of ZB: only $1 \mathrm{wt} \%$ variation of $\mathrm{ZB}$ permits to gain $100 \mathrm{~s}$ before piercing. The two ratios 27:3 and 25:5 enhance the time to piercing at $250 \mathrm{~s}$ compared to $225 \mathrm{~s}$ for the ratio 28:2. According to visual observation, the addition of $\mathrm{ZB}$ permits keeping the rigidity of the intumescent char 
undergoing the impingement of the flame and preventing too much deformation at longer times (and hence the piercing of the sample). The same experiment was done substituting $\mathrm{ZB}$ by $\mathrm{KZ}$ with the same ratio (Fig. 3 -(b)). The addition of $\mathrm{KZ}$ in the formulations $\mathrm{PP}(70)-\mathrm{FO} / \mathrm{KZ}$ permits for all ratios to dramatically enhance the time to piercing compared to the use of FO alone. The behavior looks similar and the longer time to piercing is reached at about $300 \mathrm{~s}$ for $\mathrm{PP}(70)-\mathrm{FO} / \mathrm{KZ}(25: 5)$. The same conclusion as above can be made namely the addition of $\mathrm{KZ}$ permits to reinforce the char 256 strength keeping its rigidity.

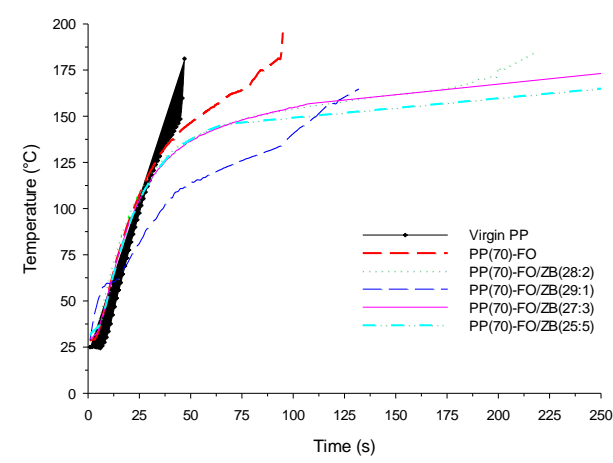

(a)

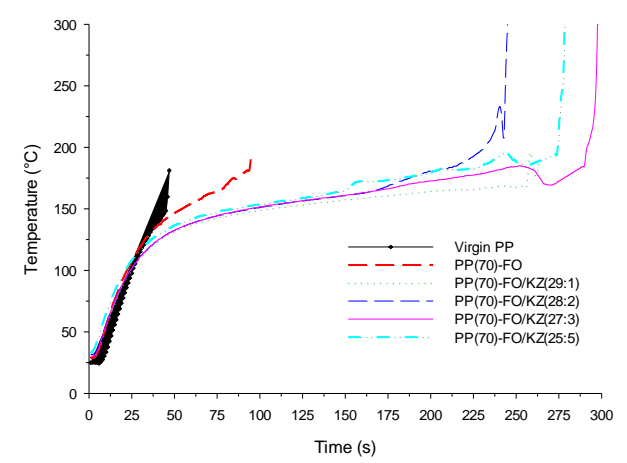

(b)

Fig. 3. Temperature as a function of time on the backside during a burn-through test at $116 \mathrm{~kW} / \mathrm{m}^{2}$ of (a) intumescent PP(70)-FO/ZB and (b) intumescent PP(70)-FO/KZ.

\subsection{Role of zinc borate}

The previous section showed the role of $\mathrm{ZB}$ reinforcing the intumescent char. Specific chemical reactions should be responsible for this reinforcement and were characterized by solid state NMR. This technique is very useful because it permits the selection of the nucleus (here ${ }^{31} \mathrm{P},{ }^{11} \mathrm{~B}$ and ${ }^{13} \mathrm{C}$ ) and to observe its surrounding. So, it gives the chemical species formed. Four materials were selected based on the results above (best ratio of $\mathrm{FO} / \mathrm{ZB}=27 / 3)$ : $\mathrm{PP}(70)-\mathrm{AP}, \mathrm{PP}(70)-\mathrm{AP} / \mathrm{ZB}(27: 3), \mathrm{PP}(70)-\mathrm{FO}$ and $\mathrm{PP}(70)-$ $\mathrm{FO} / \mathrm{ZB}(27: 3)$. Note $\mathrm{ZB}$ was used instead of $\mathrm{KZ}$ because the main component of $\mathrm{KZ}$ is $\mathrm{ZB}$ and we wanted to avoid other additional interactions. They were submitted at the burn-through test and the combustion was stopped at characteristic times namely, $50 \mathrm{~s}$ (all samples), $100 \mathrm{~s}$ (samples containing $\mathrm{FO}$ ) and $215 \mathrm{~s}$ (only $\mathrm{PP}(70)-\mathrm{FO} / \mathrm{ZB}(27: 3)$ ). The samples before testing were used as reference. 
Ammonium polyphosphate (APP) is contained in both AP and FO and is one of the main ingredients of the intumescent flame retardants (Fig. 4 at $\mathrm{t}=0 \mathrm{~s}$ ). Upon heating, APP decomposes and yields acidic phosphates acting as char promoter [3]. They play a significant role in the charring and in the formation of an intumescent coating: the evolution of the phosphate species should be revealed by ${ }^{31} \mathrm{P}$ NMR. The four samples were then characterized by DD-MAS ${ }^{31} \mathrm{P}$ NMR as a function of burning time (Fig. 4). The number of bridging oxygen atoms allows classifying the phosphate structure using $\mathrm{Q}^{\mathrm{n}}$ terminology where $\mathrm{n}$ represents the number of bridging oxygen atoms per phosphorus tetrahedron. This terminology was used in the following [9]. The spectra of the neat materials $(\mathrm{t}=0 \mathrm{~s})$ exhibit a doublet located at -22 and $-24 \mathrm{ppm}$ assigned to $\mathrm{Q}^{2}$ site. This doublet is characteristic of $\mathrm{P}$ in APP as already reported in our previous work [10]. An additional band of low intensity at $1 \mathrm{ppm}$ can be distinguished on the two FO samples. It is assigned to $\mathrm{Q}^{0}$ site probably an orthophosphate linked to aliphatic species.

At $t=50 \mathrm{~s}$, the two spectra of the samples without $\mathrm{ZB}$ exhibit three bands but not located at the same chemical shift (Fig. 4 (a) and (b)). The bands at 0 and $-12 \mathrm{ppm}$ are common for the two materials and they are assigned to $\mathrm{Q}^{0}$ site (probably mainly phosphoric acid [11]) and to $\mathrm{Q}^{1}$ site (orthophosphates linked to aromatic species [12]) respectively. It is noteworthy that the amount of species in $\mathrm{Q}^{1}$ site is higher than that in $\mathrm{Q}^{0}$ for $\mathrm{PP}(70)-\mathrm{FO}$ (ratio of the areas $\mathrm{Q}^{1} / \mathrm{Q}^{0}$ is higher). It suggests $\mathrm{FO}$ promotes the formation of phosphate linked to char. The band at $-6 \mathrm{ppm}(\mathrm{PP}(70)-\mathrm{AP})$ is attributed to $\mathrm{Q}^{2}$ sites corresponding to pyrophosphates [12] and the broad band centered at $-27 \mathrm{ppm}$ ( $\mathrm{PP}(70)-\mathrm{FO})$ is attributed to the formation of amorphous phosphate-type exhibiting $\mathrm{Q}^{3}$ and $\mathrm{Q}^{4}$ sites [13]. With the $\mathrm{ZB}$ in the formulation, the two systems have similar spectra (Fig. 4 (c) and (d)). The broad resonance (between 5 and $-55 \mathrm{ppm}$ ) is the signature of a distributed structure found in glasses or amorphous compounds while the narrow resonances are characteristic of ordered phase. It can contain zinc phosphate and borophosphate in addition to phosphate glass $[9,10]$. The two sharp bands at 0 and $-6 \mathrm{ppm}$ can be assigned as above. The band centered at $-30 \mathrm{ppm}$ is assigned to borophosphate [14] and the broad band centered at $12 \mathrm{ppm}$ might be assigned as above in a disordered structure and/or to borophosphate glass [9]. Finally, at higher testing times for $\mathrm{PP}(70)$ $\mathrm{FO} / \mathrm{ZB}(27: 3)$, the spectra are similar to those at 50s. Those results evidence APP and its decomposition products react with zinc borate. It is not unusual in intumescent systems and it was already reported in previous work [9]. The formation of borophosphate glass reinforces the char and acts as a 'glue' providing flexibility and cohesion to the char. 


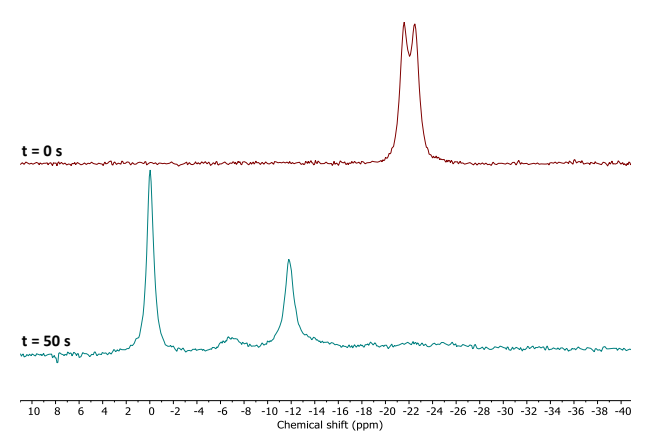

(a) $\mathrm{PP}(70)-\mathrm{AP}$

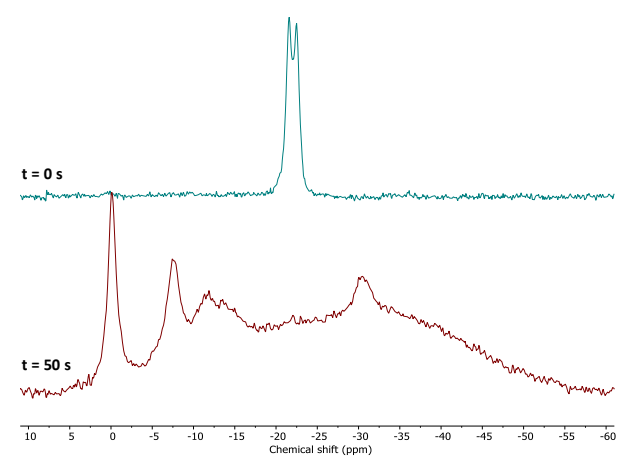

(c) $\mathrm{PP}(70)-\mathrm{AP} / \mathrm{ZB}(27: 3)$

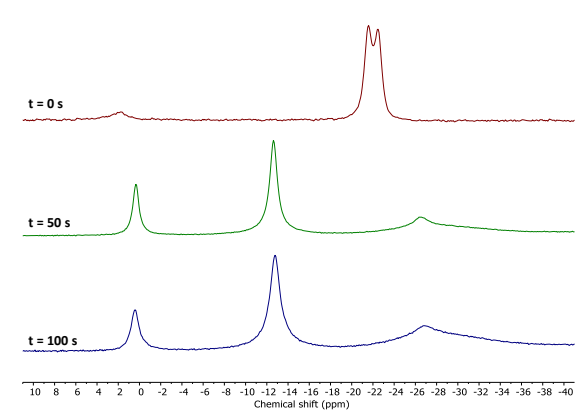

(b) PP(70)-FO

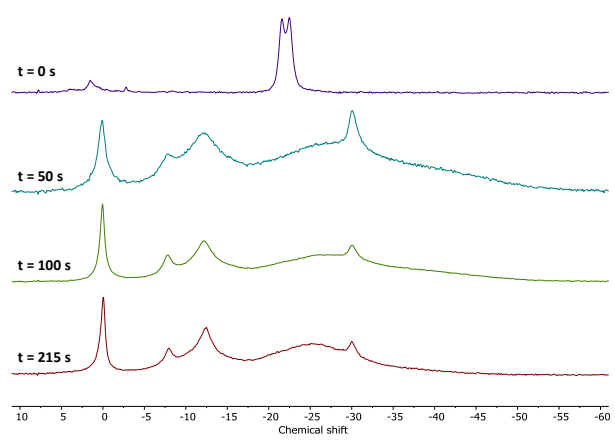

(d) $\mathrm{PP}(70)-\mathrm{FO} / \mathrm{ZB}(27: 3)$

Fig. 4. DD-MAS ${ }^{31} \mathrm{P}$ NMR of intumescent PPs as a function of burning time

318 MAS ${ }^{11} \mathrm{~B}$ NMR spectra exhibit two bands at $\mathrm{t}=0 \mathrm{~s}$ (Fig. 5). The first band lying from 10 to $20 \mathrm{ppm}$, shows the presence of trigonal $\left(\mathrm{BO}_{3}\right)$ borate units while the second band (band centered around $1 \mathrm{ppm}$ ) is assigned to tetragonal $\left(\mathrm{BO}_{4}\right)$ borate species [9]. Those two polyhedra can be characterized according to their different chemical shifts but also through their quadrupolar constant $\left(\mathrm{C}_{\mathrm{Q}}\right) . \mathrm{C}_{\mathrm{Q}}$ of $\mathrm{BO}_{3}$ is indeed much larger than that of $\mathrm{BO}_{4}$ because of the higher asymmetry of the planar $\mathrm{BO}_{3}$ species (2.4-3.0 $\mathrm{MHz}$ and $<1 \mathrm{MHz}$ for the $\mathrm{BO}_{3}$ and $\mathrm{BO}_{4}$ units, respectively) [15]. This explains why $\mathrm{BO}_{3}$ signals are broader than $\mathrm{BO}_{4}$ resonances. After burning $(\mathrm{t}>0 \mathrm{~s})$, the broad band assigned to $\mathrm{BO}_{3}$ units disappears and the band assigned to $\mathrm{BO}_{4}$ units is shifted to -4 ppm (Fig. 5). The spectra are similar for the two formulations and whenever the duration of testing. A main sharp band can be distinguished at $-4 \mathrm{ppm}$ and a shoulder at $-1.5 \mathrm{ppm}$ which are assigned to two types of borophosphates [16]. It is consistent with the assignments of the DD-MAS ${ }^{31} \mathrm{P}$ NMR spectra. Borates react with 
phosphates upon heating and they are all consumed by the reaction: they are no longer 'free' borates in the intumescent coating.

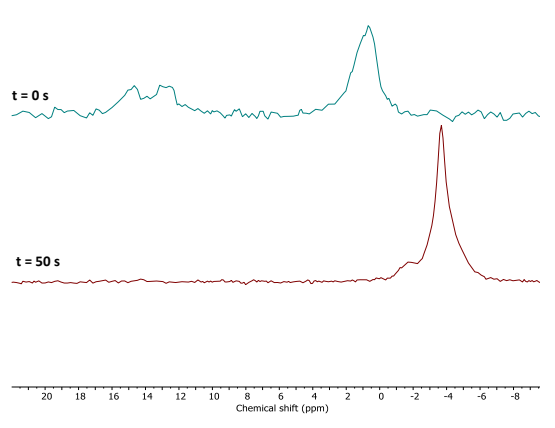

(a) $\mathrm{PP}(70)-\mathrm{AP} / \mathrm{ZB}(27: 3)$

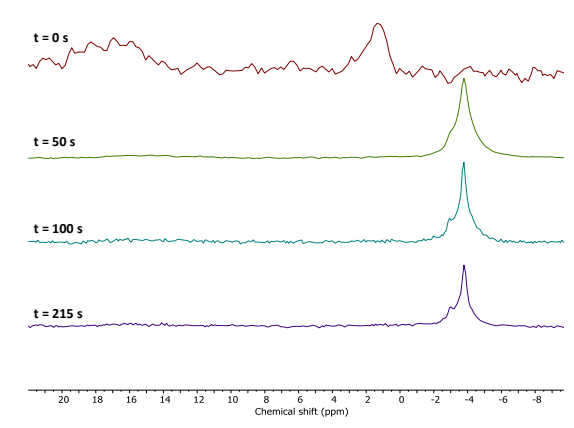

(b) $\mathrm{PP}(70)-\mathrm{FO} / \mathrm{ZB}(27: 3)$

Fig. 5. MAS ${ }^{11} \mathrm{~B}$ NMR of intumescent PPs containing $\mathrm{ZB}$ as a function of burning time

The basic principle of intumescence is to make a protective char. Visual observation of the behavior of the materials evidences the charring of the 4 systems and hence, ${ }^{13} \mathrm{C}$ NMR should provide information on carbonaceous species formed upon burning. All CP-DD-MAS ${ }^{13} \mathrm{C}$ NMR spectra exhibit three resonance bands located at 21, 26 and 43 ppm (Fig. 6). They can be assigned to polymeric chains of PP where the bands at 21,26 and $43 \mathrm{ppm}$ are assigned to $\mathrm{CH}_{3}, \mathrm{CH}$ and $\mathrm{CH}_{2}$ groups respectively [17]. For the sake of brevity, the spectra at $\mathrm{t}=0 \mathrm{~s}$ were not shown because they only exhibit the three mentioned bands and no additional insight was provided. It is noteworthy the bands of PP are detected whenever the duration of testing. It makes sense because the test is stopped when piercing occurs due to the softening of PP. PP is therefore not completely decomposed and so, it can be detected by NMR.

Intumescent char is constituted by condensed polyaromatic species containing mainly carbon and sometimes heteroatoms like nitrogen and oxygen $[18,19]$. They are then detected by solid state NMR of carbon by a broad band centered around $130 \mathrm{ppm}$ corresponding to $\mathrm{sp}^{2}$ hybridized aromatic carbon atoms. Except for the samples containing FO, this band cannot be detected with our experimental conditions (even when zooming in) (Fig. 6). Two phenomena could explain this: (i) CP was used for the acquisition of the spectra and because of the low number of protons on aromatic rings, the magnetization transfer is low and hence, the intensity of the band is low or undetectable and (ii) the formation of carbon free radicals on aromatic ring creates a strong anisotropy of magnetic susceptibility and then the loss of NMR signal [12]. Charring occurs for each sample and when detectable, a broad band centered at $125 \mathrm{ppm}$ can be distinguished. On the 
spectra recorded on FO containing samples at $50 \mathrm{~s}$ (Fig. 6-b) and at $100 \mathrm{~s}$ (Fig. 6-d), a tail to the higher ppm is observed. It suggests the formation of oxidized carbons and of aromatic carbons bound to phosphates [20]. Additional bands can be distinguished on the spectrum of $\operatorname{PP}(70)$ $\mathrm{FO} / \mathrm{ZB}(27: 3)$ at $\mathrm{t}=215 \mathrm{~s}$ (Fig. 6-d) located at 111, 121, 125 and $143 \mathrm{ppm}$. They are relatively sharp on the broad band corresponding to the aromatic carbons. The band at $111 \mathrm{ppm}$ is assigned to protonated aromatic carbon, those at 121 and $125 \mathrm{ppm}$ are assigned to non-protonated aromatic carbons and that at $143 \mathrm{ppm}$ is assigned to aromatic carbons bound with phosphates [20]. The shape of the 4 bands indicate carbon atoms are in an environment of higher symmetry suggesting the formation of some crystalline species. Overall, it is shown phosphates can be bound to the charred structure. The presence of phosphate prevents the oxidation of 'carbons' [21] and provides additional mechanical properties to the char (higher char strength and flexibility) [22].

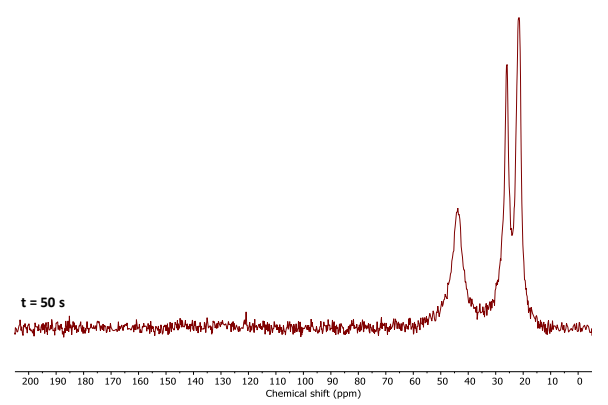

(a) $\mathrm{PP}(70)-\mathrm{AP}$

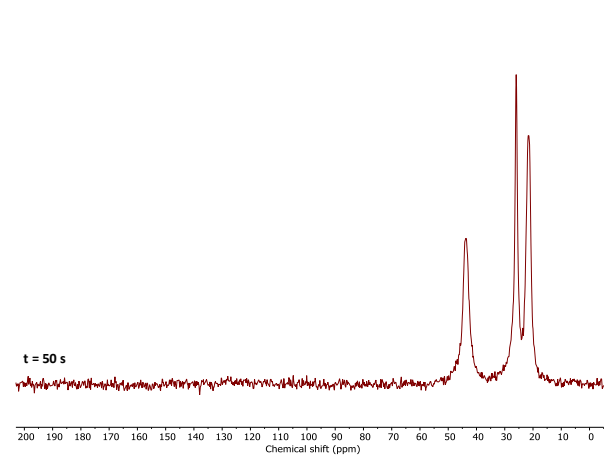

(c) $\mathrm{PP}(70)-\mathrm{AP} / \mathrm{ZB}(27: 3)$

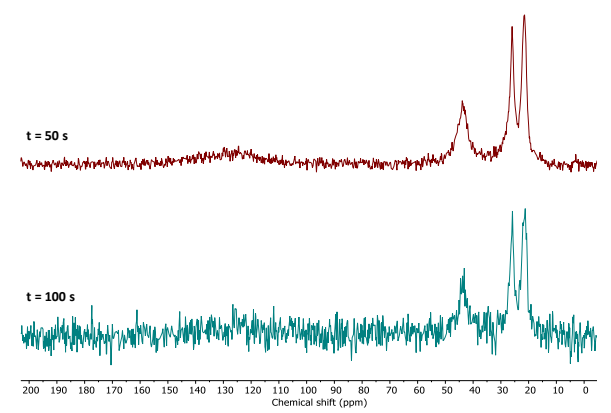

(b) $\mathrm{PP}(70)-\mathrm{FO}$

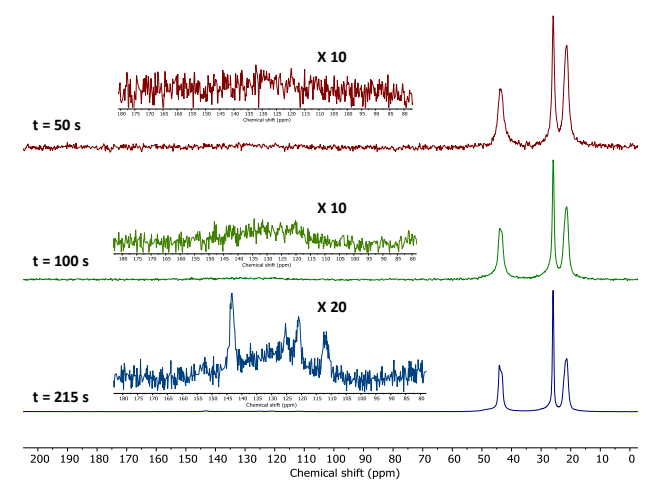

(d) $\mathrm{PP}(70)-\mathrm{FO} / \mathrm{ZB}(27: 3)$ 


\subsection{Effect of loading}

382 The first section showed that $\mathrm{ZB}$ and $\mathrm{KZ}$ in combination with FO provide superior performance at the burn-through test. The purpose is to increase the total loading of fillers (at $50 \mathrm{wt} \%$ ) in PP to investigate its effect in terms of time to piercing. The time/temperature curves of all formulations are shown on Fig. 7. Surprisingly, the curves of the formulations containing ZB does not show any improvement compared to those at $30 \mathrm{wt} \%$ loading (Fig. $3 \mathrm{vs}$. Fig. 7). It is also true for the formulations containing $\mathrm{KZ}$ (times to piercing are even shorter) except for the ratio FO/KZ at 25 to 5 (Fig. 7-b). In this last case, the time to piercing reaches $330 \mathrm{~s}$ compared to the others exhibiting a time to piercing at $175 \mathrm{~s}$. At high loading, it is observed higher charring but at the same time, the material looks softer. So, it implies that the impingement of the flame creates the piercing at shorter times because of its lower viscosity even if its efficiency as heat barrier might be higher.

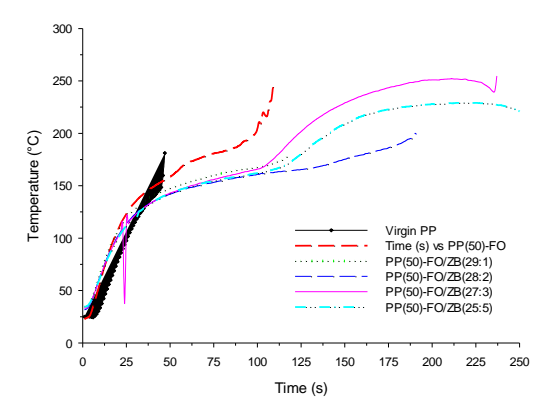

(a)

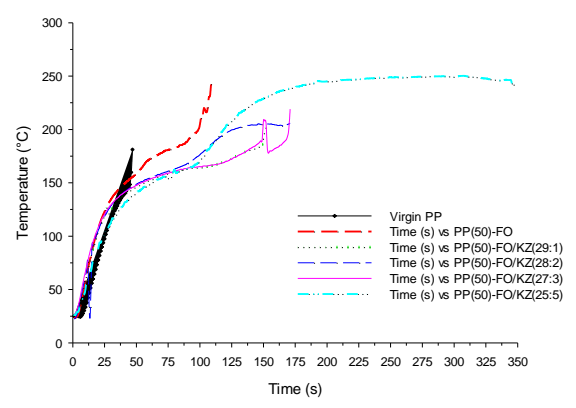

(b)

Fig. 7. Temperature as a function time on the backside during a burn-through test at 116 $\mathrm{kW} / \mathrm{m}^{2}$ of (a) intumescent $\mathrm{PP}(50)-\mathrm{FO} / \mathrm{ZB}$ and (b) intumescent $\mathrm{PP}(50)-\mathrm{FO} / \mathrm{KZ}$.

\section{Conclusion}

This paper showed that intumescent PP could be designed to resist to burnthrough test. The selection of the intumescent system (or in another words the chemistry of the system) is essential to get long time to piercing (e.g. $100 \mathrm{~s}$ vs. $40 \mathrm{~s}$ when using FO instead of AP) and a synergist can dramatically extend the time to piercing (e.g. $215 \mathrm{~s}$ vs. $100 \mathrm{~s}$ when using FO/ZB instead of FO alone). Analyzing the residues obtained at different times of combustion by solid state NMR of ${ }^{31} \mathrm{P},{ }^{11} \mathrm{~B}$ and ${ }^{13} \mathrm{C}$, it is shown that phosphates were bound to the charred structure (in the case of FO containing systems) and that the formation of borophosphates created a glass reinforcing the intumescent char. This combination provides flexibility and cohesion to the char. The unusual fire resistance of FR plastics paves the way to other applications where burnthrough scenario can be involved. Such 
scenario might happen in plants if leak of flammable products occurs creating a torch impinging surrounded plastics. The fire resistance of our formulations might bring therefore additional fire safety.

\section{Acknowledgement}

This work has received funding from the European Research Council (ERC) under the European Union's H2020- the framework programme for Research and Innovation (2014-2020) ERC Grant Advances Agreement N670747-ERC 2014 AdG/FireBar-Concept for FireBar Concept project.

\section{References}

[1] Viegas DX. Extreme fire behaviour. In. Extreme fire behaviour. Nova Science Publishers, Inc., 2012, pp. 1-56.

[2] La Delfa G, Luinge JW, Gibson AG, Integrity of composite aircraft fuselage materials under crash fire conditions, Plastics, Rubber and Composites, 2009;38: 111-17.

[3] Alongi J, Han Z, Bourbigot S, Intumescence: Tradition versus novelty. A comprehensive review, Progress in Polymer Science, 2015;51: 28-73.

[4] Jimenez M, Duquesne S, Bourbigot S, Multiscale Experimental Approach for Developing High-Performance Intumescent Coatings, Industrial \& Engineering Chemistry Research, 2006;45: 4500-08.

[5] Bourbigot S, Sarazin J, Bensabath T, Samyn F, Jimenez M, Intumescent polypropylene: Reaction to fire and mechanistic aspects, Fire Safety Journal, 2019;105: 261-69.

[6] Casetta M, Delaval D, Traisnel M, Bourbigot S, Influence of the recycling process on the fire-retardant properties of PP/EPR blends, Macromolecular Materials and Engineering, 2011;296: 494-505.

[7] Fontaine G, Bourbigot S, Duquesne S, Neutralized flame retardant phosphorus agent: Facile synthesis, reaction to fire in PP and synergy with zinc borate, Polymer Degradation and Stability, 2008;93: 68-76.

[8] Tranchard P, Samyn F, Duquesne S, Thomas M, Estèbe B, Montès JL, Bourbigot S, Fire behaviour of carbon fibre epoxy composite for aircraft: Novel test bench and experimental study, Journal of Fire Sciences, 2015;33: 247-66.

[9] Hansupo N, Tricot G, Bellayer S, Roussel P, Samyn F, Duquesne S, Jimenez M, Hollman M, Catala P, Bourbigot S, Getting a better insight into the chemistry of decomposition of complex flame retarded formulation: New insights using solid state NMR, Polymer Degradation and Stability, 2018;153: 145-54.

[10] Samyn F, Bourbigot S, Duquesne S, Delobel R, Effect of zinc borate on the thermal degradation of ammonium polyphosphate, Thermochimica Acta, 2007;456: 134-44.

[11] Sut A, Greiser S, Jäger C, Schartel B, Synergy in flame-retarded epoxy resin: Identification of chemical interactions by solid-state NMR, Journal of Thermal Analysis and Calorimetry, 2017;128: 141-53.

[12] Bourbigot S, Le Bras M, Delobel R, Decressain R, Amoureux JP, Synergistic effect of zeolite in an intumescence process: Study of the carbonaceous structures using solidstate NMR, Journal of the Chemical Society - Faraday Transactions, 1996;92: 149-58. [13] Mercier C, Montagne L, Sfihi H, Palavit G, Boivin JC, Legrand AP, Local structure 456 of zinc ultraphosphate glasses containing large amount of hydroxyl groups: $31 \mathrm{P}$ and $1 \mathrm{H}$ 
solid state nuclear magnetic resonance investigation, Journal of Non-Crystalline Solids, 1998;224: 163-72.

[14] Jimenez M, Duquesne S, Bourbigot S, Intumescent fire protective coating: Toward a better understanding of their mechanism of action, Thermochimica Acta, 2006;449: 16-

46126.

[15] Hansen MR, Madsen GKH, Jakobsen HJ, Skibsted J, Refinement of borate structures from11B MAS NMR spectroscopy and density functional theory calculations of 11B electric field gradients, Journal of Physical Chemistry A, 2005;109: 1989-97. [16] Tricot G, Raguenet B, Silly G, Ribes M, Pradel A, Eckert H, P-O-B3 linkages in borophosphate glasses evidenced by high field 11B/31P correlation NMR, Chemical Communications, 2015;51: 9284-86. [17] Laupretre F, Bebelman S, Daoust D, Devaux J, Legras R, Costa JL, NMR, differential scanning calorimetry, and fourier transform infrared characterization of the crystalline degree and crystallite dimensions of ethylene runs in isotactic polypropylene/ethylene-propylene copolymer blends (iPP/EP), Journal of Applied Polymer Science, 1999;74: 3165-72.

[18] Bourbigot S, Le Bras M, Delobel R, Breant P, Tremillon J-M, Carbonization mechanisms resulting from intumescence - part II. Association with an ethylene terpolymer and the ammonium polyphosphate-pentaerythritol fire retardant system, Carbon, 1995;33: 283-94.

[19] Bourbigot S, Le Bras M, Delobel R, Gengembre L, XPS study of an intumescent coating II. Application to the ammonium polyphosphate/pentaerythritol/ethylenic terpolymer fire retardant system with and without synergistic agent, Applied Surface Science, 1997;120: 15-29.

[20] Karrasch A, Wawrzyn E, Schartel B, Jäger C, Solid-state NMR on thermal and fire residues of bisphenol A polycarbonate/silicone acrylate rubber/bisphenol A bis(diphenylphosphate)/(PC/ SiR/BDP) and PC/SiR/BDP/zinc borate (PC/SiR/BDP/ZnB) - Part I: PC charring and the impact of BDP and ZnB, Polymer Degradation and Stability, 2010;95: 2525-33.

[21] McKee DW, Spiro CL, Lamby EJ, The inhibition of graphite oxidation by phosphorus additives, Carbon, 1984;22: 285-90. intumescence process: Study of the interactions between the polymer and the additives, 